\title{
Proficiência e atitudes linguísticas de estudantes Kaingang de ensino fundamental e médio da terra indígena de Faxinal (Cândido de Abreu/PR): diagnóstico inicial
}

\author{
Elisangela Wilchak Queiroz \\ Universidade Estadual de Ponta Grossa (UEPG), Ponta Grossa, Paraná, Brasil \\ elisangelawq@gmail.com.br \\ https://orcid.org/0000-0002-1357-3938
}

DOI: http://dx.doi.org/10.21165/el.v47i1.1942

\begin{abstract}
Resumo
Este trabalho tem como objetivo apresentar um estudo sobre as atitudes manifestadas em relação às línguas portuguesa e kaingang por crianças e adolescentes indígenas da Terra Indígena de Faxinal, município de Cândido de Abreu/PR, estudantes do Colégio Estadual Indígena Professor Sergio Krigrivaya Lucas. Do ponto de vista teórico, para discutir a questão das atitudes linguísticas nos baseamos em Corbari (2012). Metodologicamente, realizamos uma pesquisa quali-quantitativa com alunos do $6^{\circ}$ ano do Ensino Fundamental ao $3^{\circ}$ ano do Ensino Médio, do referido Colégio Estadual Indígena. Cada aluno respondeu a um questionário de perguntas abertas que permitiram fazer um levantamento sobre as atitudes relativas às línguas Kaingang e portuguesa.
\end{abstract}

Palavras-chave: atitudes linguísticas; identidade; língua.

Habilidades y actitudes linguísticas de estudiantes Kaingang de enseñanza fundamental y media de la tierra indígena de Faxinal (Cândido de Abreu/PR): diagnóstico inicial

\section{Resumen}

Este trabajo tiene como objetivo presentar un estudio sobre las actitudes manifestadas en relación a las lenguas portuguesa y kaingang por niños y adolescentes indígenas de la Tierra Indígena de Faxinal, municipio de Cândido de Abreu/PR, estudiantes del Colegio Estatal Indígena Profesor SergioKrigriyaya Lucas. Desde el punto de vista teórico, para discutir la cuestión de las actitudes linguísticas nos basamos en Corbari (2012). Metodológicamente, realizamos una investigación cuali-cuantitativa con alumnos del $6^{\circ}$ año de la Enseñanza Fundamental al $3^{\circ}$ año de la Enseñanza Media, del referido Colegio Estatal Indígena. Cada alumno respondió a un cuestionario de preguntas abiertas que permitieron hacer un estudio sobre las actitudes relativas a las lenguas kaingang y portuguesa.

Palabras-clave: actitudes linguísticas; identidad; lengua.

\section{Introdução}

As perguntas que tentamos responder no decorrer dessa pesquisa referem-se ao valor atribuído pelos indígenas à língua Kaingang e portuguesa e ao papel que cada uma dessas línguas exerce dentro do grupo.

Sendo assim, trazemos como objetivo geral identificar a proficiência em português e Kaingang de crianças e adolescentes Kaingang de Faxinal, bem como as atitudes linguísticas que esses manifestam em reação às mesmas línguas. Como objetivos específicos, pretendemos identificar o nível de proficiência em português, na visão dos 
próprios participantes, em cada uma das habilidades; reconhecer o nível de proficiência em Kaingang, na visão dos próprios participantes, em cada uma das habilidades; fazer um levantamento das atitudes manifestadas pelos participantes em relação à língua portuguesa e fazer um levantamento das atitudes manifestadas pelos participantes em relação à língua Kaingang.

\subsection{Conhecendo a Terra Indígena de Faxinal}

A Terra Indígena de Faxinal, local onde esta pesquisa foi realizada, se localiza bem ao centro do estado do Paraná, pertencente ao município de Cândido de Abreu. Possui uma área de 2.043,9 hectares e uma população de aproximadamente 600 pessoas, da etnia Kaingang (IBGE, 2012).

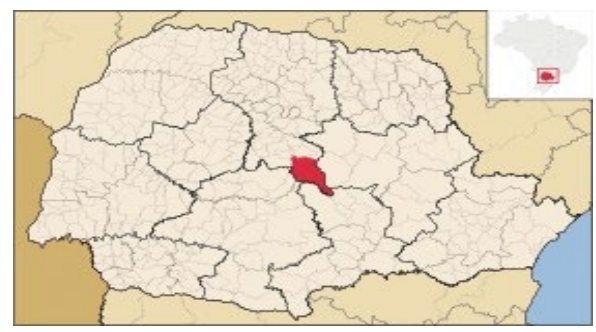

Mapa 1 - Município de Cândido de Abreu, no Paraná, onde se localiza a Terra Indígena de Faxinal. Fonte: Google Maps

Existem no Paraná as etnias Kaingang, Guarani e Xetá. Ao todo são aproximadamente 9.015 indígenas que habitam um total de 85.264,30 hectares de terras, distribuídos em 17 Terras Indígenas, como se pode observar no Mapa 2.

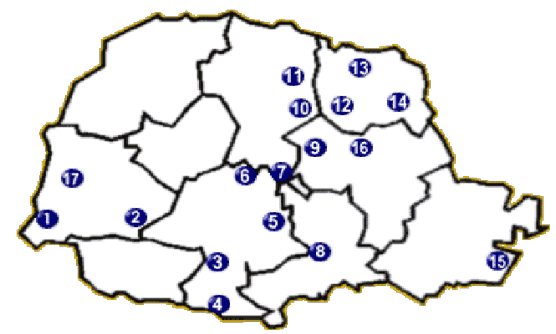

Mapa 2 - Terras Indígenas localizadas no Estado do Paraná.

Fonte: Google Maps 
Quadro 1 - Nome das Terras Indígenas demarcadas no Estado do Paraná

\begin{tabular}{|c|l|c|l|}
\hline 1 & Reserva Indígena Ocoí & 10 & Reserva Indígena Apucaraninha \\
\hline 2 & Reserva Indígena Rio das Cobras & 11 & Reserva Indígena Barão de Antonina \\
\hline 3 & Reserva Indígena de Mangueirinha & 12 & Reserva Indígena São Jerônimo da Serra \\
\hline 4 & Reserva Indígena de Palmas & 13 & Reserva Indígena Laranjinha \\
\hline 5 & Reserva Indígena Marrecas & 14 & Reserva Indígena Pinhalzinho \\
\hline 6 & Reserva Indígena Ivaí & 15 & Reserva Indígena Ilha da Cotinga \\
\hline 7 & Reserva Indígena Faxinal & 16 & Reserva Indígena Mococa \\
\hline 8 & Reserva Indígena Rio D'Areia & 17 & Reserva Indígena Tekoha-Añetetê \\
\hline 9 & Reserva Indígena Queimadas & & \\
\hline
\end{tabular}

Fonte: Google Maps

Além do Paraná, os Kaingang habitam também o estado de São Paulo, Santa Catarina e Rio Grande do Sul, mas há anos eles ocupavam um território muito maior. De acordo com os apontamentos de Neolli (2002, p. 243 apud RODRIGUES, 2012, p. 62), os Kaingang:

Apontados pelo Instituto Socioambiental - ISA - como a terceira maior população indígena em número de indivíduos - mais de 24 mil pessoas - o povo Kaingang é considerado herdeiro ou remanescente de populações caçadoras-coletoras préceramistas que viveram no território hoje chamado de Brasil, desde aproximadamente 2500 anos antes do presente.

Ainda para Soares (2008, p. 45 apud RODRIGUES, 2012, p. 62), "os Kaingang são os descendentes dos povos pertencentes à Tradição Taquara, um povo que era construtor de casas subterrâneas e que viveu entre 8000 a 2000 anos a.p. nas regiões do sul do Brasil, parte da Argentina e do Paraguai".

Os Kaingang viveram livres na região do sul do país até o século XIX quando houve a ocupação do território pelos não indígenas. As primeiras tentativas de ocupação das terras indígenas Kaingang, Guarani, Xokleng e Xetá iniciaram-se no estado do Paraná. A reação dos indígenas foi muito violenta. Os brancos que tentavam ocupar o território, até então habitado apenas pelos indígenas, trouxeram presentes para os indígenas com o intuito de ganhar a confiança deles. No entanto, isso não aconteceu e as expedições tiveram que abandonar seus postos, voltando apenas 40 anos depois.

Hoje na Reserva Indígena de Faxinal habitam indígenas da etnia Kaingang, falantes da língua indígena denominada também Kaingang, que é pertencente ao tronco linguístico Macro-Jê. Segundo Rodrigues (2012, p. 61): "O termo Kanhgág ou Kaingang quer dizer homem ou homem do mato".

Algumas Terras Indígenas paranaenses são compostas de indígenas de etnias distintas, como é o caso da T.I. de Mangueirinha e do Rio das Cobras, em que vivem indígenas Kaingang e Guarani. Cada etnia possui seu cacique e os outros membros da liderança. De acordo com Rodrigues (2012, p. 93), na Terra Indígena de Faxinal, 
Não há divisão em aldeias. A população reside ao entorno dos postos de serviços existentes - o extinto escritório da Funai, a escola, o posto de saúde, as igrejas, o clube de baile, a pastoral da criança. As residências estão construídas próximas umas das outras, formando uma área central.

Com relação à política, a escolha do cacique é feita por votação. O que receber mais votos fica no posto por quatro anos. No entanto, segundo Rodrigues (2012, p. 117): "uma das primeiras lições que aprendi sobre os Kaingang foi a de que o chefe é um subalterno da comunidade. Ele está cacique hoje, amanhã, se desagradar seus pares pode não estar mais".

Há algum tempo, os professores indígenas vêm participando de cursos de formações, o que propicia, segundo Rodrigues (2012, p. 132), "O resgate e a preservação das tradições e costumes". Durante os seus cursos e convivência com não indígenas, eles vão internalizando e incorporando os conteúdos que aprendem no cotidiano. Não são muito apegados ao passado, porque muitas vezes o passado não traz boas recordações. Muitos passaram fome, não tinham casa, viviam muito precariamente. Eram épocas muito difíceis, e agora consideram que vivem bem melhor do que antes, um dos motivos pelos quais não thes faz bem recordar o passado.

É um povo de tradição oral, mas que, aos poucos, vem agregando à sua cultura também a escrita. Isso ocorre principalmente devido ao processo de escolarização, pois há vários alunos cursando o ensino médio e superior. A influência da formação dos não indígenas causa esta associação da preservação da cultura e de seus saberes à escrita, $o$ que não quer dizer que a oralidade acabará. O que ocorreu foi que, mesmo depois de tanta violência e imposições que sofreram, houve uma reinvenção e atualização da sua forma de viver. Ainda nos dias de hoje, há muitos professores não indígenas nas escolas das aldeias, mas a tendência é mudar esta realidade, pois os indígenas estão cada vez mais à procura de formação, almejando um dia ter nas escolas das aldeias indígenas uma maioria de professores indígenas.

\subsection{Realidade linguística da T.I. de Faxinal: o que dizem os dados do último Censo}

Por meio dos dados coletados no Censo de 2010, podemos ter acesso a algumas informações referentes à comunidade indígena de Faxinal no Paraná. Os dados estão disponíveis no site do IBGE para consulta a todos os interessados. Os que vamos utilizar nesta pesquisa são os dados referentes à autodeclaração como indígenas e os que dizem respeito "à condição de falar língua indígena no domicílio". ${ }^{1}$

Na Figura 1, temos o total de habitantes até o ano de 2010, cerca de 600 pessoas - como já mencionamos - que se declaram indígenas e um número muito pequeno, cerca de $1 \%$, que não se declara indígena, mas se considera.

\footnotetext{
${ }^{1}$ Esclarecemos que, a partir dos dados do Censo (IBGE, 2010), fazemos observações apenas sobre uso de língua indígena, pois a pesquisa não fornece dados sobre uso de língua portuguesa.
} 


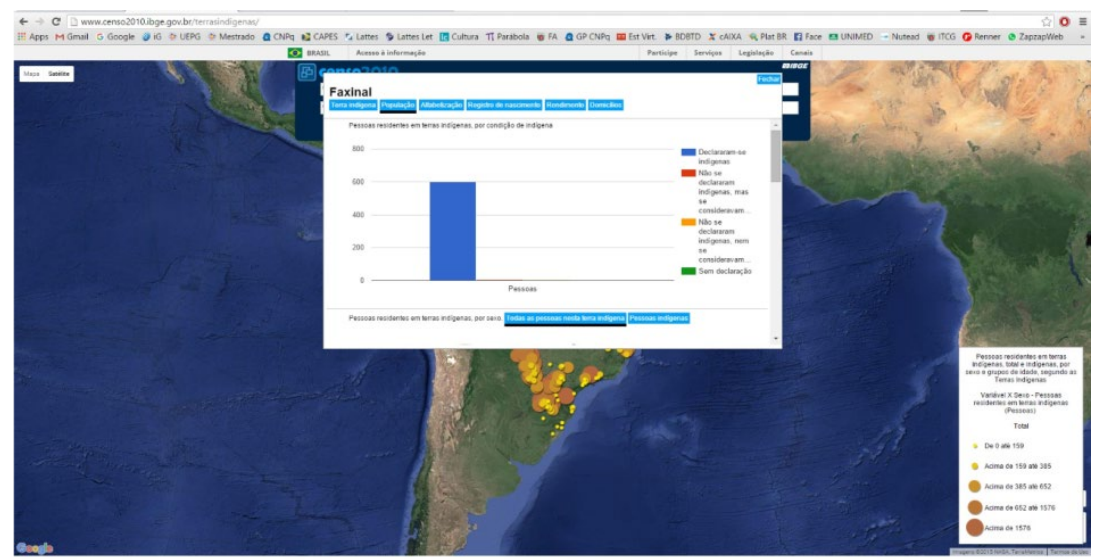

Figura 1 - Quantidade de pessoas residentes na T.I. de Faxinal, por condição de indígena Fonte: IBGE (2010)

A diferença entre se declarar e se considerar indígena, para o IBGE, é que o primeiro é oriundo de resposta à pergunta sobre a etnia do entrevistado. Já a "consideração" é fruto de pergunta específica a ser feita em Terras Indígenas, a quem não se autodeclarava indígena, na pergunta sobre a etnia. Em Faxinal, como os dados mostram, a autodeclaração é recorrente, o que pode significar que a visão de si mesmo como indígena não é uma questão.

A Figura 2 refere-se ao número de pessoas que se declaram falantes de língua indígena em domicílio. Do total de habitantes da comunidade, 98,7\% se declararam falantes de língua indígena. Apesar de o número de pessoas que não declararam falar língua indígena ser muito pequeno, é importante ressaltar que isso não significa que estas não saibam de fato. Muitas vezes, isso ocorre em função da insegurança que a condição de bilíngue proporciona. Segundo Frosi, Faggion e Dal Corno (2010, p. 39): "A insegurança provém da sensação que nenhuma das duas línguas foi totalmente aprendida", ou seja, devido à constante exposição dos falantes indígenas às duas línguas, indígena e portuguesa, tem-se a "sensação" de não possuir conhecimento suficiente em nenhuma das línguas a ponto de declarar isso.

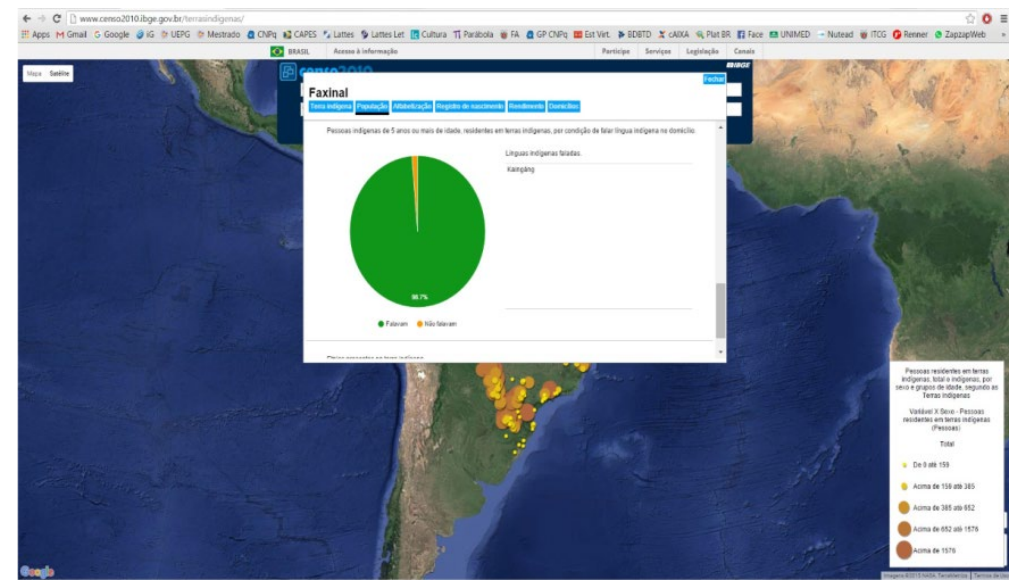

Figura 2 - Quantidade de falantes de língua indígena no domicílio residentes na T.I. de Faxinal Fonte: IBGE (2010) 


\subsection{Língua materna e segunda língua/língua estrangeira}

Quando falamos em língua materna (doravante LM), a definição do senso comum é a de que esta é a primeira língua que aprendemos e a que mais falamos, portanto em que temos grande proficiência: "É a língua que aprendemos em casa, ou a primeira língua". Já a segunda língua (doravante SL) e língua estrangeira (doravante LE) seria(m) aquela(s) "para além" da LM, língua em que, ao contrário da LM, temos uma proficiência menor. Por fim, ainda na perspectiva do senso comum, um indivíduo é considerado bilíngue quando "domina" duas línguas, as "fala bem", de modo que manifesta uma proficiência semelhante em ambas.

Por outro lado, na literatura da área, os conceitos não são tão simples ou simplificados. No que se refere à LM, Spinassé (2006, p. 5.) a define como Língua (L1), com alguns aspectos que devem ser levados em conta:

A Língua Materna, ou a Primeira Língua (L1) não é, necessariamente, a língua da mãe, nem a primeira língua que se aprende. Tampouco trata-se de apenas uma língua. Normalmente é a língua que aprendemos primeiro e em casa, através dos pais, e também é frequentemente a língua da comunidade. Entretanto, muitos outros aspectos linguísticos e não-linguísticos estão ligados à definição. A língua dos pais pode não ser a língua da comunidade, e, ao aprender as duas, o indivíduo passa a ter mais de uma L1 (caso de bilinguismo). Uma criança pode, portanto, adquirir uma língua que não é falada em casa, e ambas valem como L1.

O status da LM pode variar, portanto, tal como vimos no exemplo acima. Por isso, conceituar o que vem a ser LM é algo mais difícil do que parece. É preciso levar em conta o contexto e os vários aspectos citados por Spinassé (2006). Segundo ela, para classificar uma língua como LM não se deve apenas considerar a língua que aprendemos primeiro, mas todos os outros fatores que envolvem o uso da língua. Além da LM, há em muitas situações também a SL e, no que se refere a ela, Spinassé $(2006$, p. 6) afirma que esta "[...] não é necessariamente uma segunda, no sentido de que haverá uma terceira, uma quarta, e assim por diante. 'Segunda' está para 'outra que não a primeira (a materna)"'. No entanto, isso não quer dizer que toda língua que aprendemos depois da LM seja uma SL, pois tudo vai depender de como se dá o uso de cada uma delas. Para Spinassé (2006, p. 6):

Diferenciando, porém, do conceito de Língua Estrangeira (LE), uma Segunda Língua é uma não-primeira-língua que é adquirida sob a necessidade de comunicação e dentro de um processo de socialização. A situação tem que ser favorável: um novo meio, um contato mais intensivo com uma nova língua que seja importante para a comunicação e para a integração social. Para o domínio de uma SL é exigido que a comunicação seja diária e que a língua desempenhe um papel na integração em sociedade. Do contrário, no processo de aprendizado de uma LE não se estabelece um contato tão grande ou tão intenso com a mesma. A grande diferença é que a LE não serve necessariamente à comunicação $\mathrm{e}$, a partir disso, não é fundamental para a integração, enquanto a SL desempenha um papel até mesmo vital numa sociedade. (SPINASSÉ, 2006, p. 6). 


\subsection{Escola Indígena Bilíngue}

Para algumas comunidades indígenas paranaenses, como é o caso da comunidade em que este trabalho foi realizado, o bilinguismo é uma realidade vivida todos os dias. Trata-se de uma condição praticamente obrigatória, pois os indígenas falam língua indígena e precisam saber português, que é a língua dominante na escola, na cidade e nos contatos com quaisquer não indígenas. Segundo Almeida (2011, p. 3992),

O Bilinguismo para os indígenas assume um caráter compulsório. A esses não é dada a possibilidade de escolha. $\mathrm{O}$ domínio da língua portuguesa é uma obrigação. Tanto na situação de contato com a sociedade majoritária, quanto em diferentes domínios sociais das aldeias, existe uma "necessidade imperiosa" de falar português, sendo a questão do "pertencimento" um dos fatores que se sobrepõem, apresentando-se mesmo como prioridade, principalmente para jovens e adolescentes.

Partindo do princípio de que a língua portuguesa é imposta aos indígenas, houve a necessidade de se organizar a escola indígena de forma que a escola dentro da aldeia se torne algo positivo e não mais um meio de intervenção na cultura, língua e vida desses povos.

Desta forma, as primeiras Diretrizes Nacionais para a Educação Escolar Indígena foram propostas em 1999 pelo Conselho Nacional da Educação através da sua Câmara de Educação Básica. As normas foram fixadas pelo Parecer CNE/CEB 14/99 e a Resolução CNE/CEB 3/99 e outras legislações baseadas na Constituição de 1988. Essas normas vêm com o objetivo de orientar que todas as escolas situadas em Terras Indígenas no Brasil sejam diferenciadas em currículo, calendário, professores, materiais didáticos, de modo que haja uma articulação entre a cultura indígena e a cultura da população dominante no país. Por isso, é preciso que a escola seja bilíngue, fazendo uso da língua indígena e portuguesa em todo o processo educacional de ensino e aprendizagem dos alunos indígenas.

De modo geral, a partir dos dados levantados para a elaboração desta pesquisa na Escola Estadual Indígena Professor Sérgio Krigrivaja Lucas, na Terra Indígena de Faxinal, pudemos observar que, apesar de a comunidade indígena utilizar a língua materna Kaingang para se comunicar no cotidiano, a língua portuguesa está também muito presente, principalmente na escola, entre os adolescentes. Já as crianças e os mais velhos demonstraram que têm mais dificuldade em falar português, pois são os que têm menos contato com a língua portuguesa, a maior parte das crianças chega à escola falando apenas a língua indígena. Esses resultados fazem com que se reflita em que termos a referida escola atende as Diretrizes Nacionais para a Educação Escolar Indígena, no sentido de realizar um trabalho bilíngue que tanto dê aos indígenas subsídios para a interação com a sociedade fora da aldeia por meio da língua portuguesa quanto promova a valorização da língua indígena.

Nesse sentido, na sequência faremos algumas reflexões sobre as noções que apresentamos nas seções anteriores na visão dos indígenas, pois eles são os principais interessados em ter uma escola de qualidade, que atenda suas demandas linguísticas, que podem não ser colocadas do mesmo modo como fazem as Diretrizes ou mesmo os estudos sobre bilinguismo na Linguística Aplicada. 


\subsection{A noção de Língua Materna para os indígenas}

Na seção 2.1 deste trabalho, trouxemos o conceito de LM tal como proposto nos estudos da Linguística Aplicada. No entanto, é importante ressaltar que as proposições dos teóricos são passíveis de revisão e discussão, considerando-se que a todo momento podemos ter conhecimento de situações linguísticas até então ignoradas. Ou seja, nosso objetivo é mostrar que, quando se trata de língua, devemos manter a mente aberta para novas possibilidades.

Retomando o conceito de Spinassé (2006), a língua materna não é apenas a que aprendemos primeiro. Ela pode inclusive mudar, se uma segunda língua vir a se tornar uma língua materna para determinado indivíduo, dependendo do contexto em que está inserido. É uma realidade totalmente considerável, levando em conta os exemplos dados pela autora, afinal, para cada indivíduo a função da língua é mutável e nós a adequamos de acordo com nossas necessidades.

No entanto, já há levantamentos (NASCIMENTO, 2014) indicando que, para indígenas brasileiros, a língua materna é a língua indígena, independentemente se eles a aprenderam primeiro ou depois, na escola, ou mesmo se não a falam ou falam pouco. A noção de língua materna tem mais a ver com identidade como indígena, portanto, na Terra Indígena de Faxinal, a língua materna de quase a totalidade dos indígenas é o Kaingang, porque de fato é a língua mais falada (em muitos casos a única), conforme dados levantados para este trabalho e os do último Censo (IBGE, 2010); é também a língua que ratifica a identidade como indígena.

Por essa razão, no caso de um indígena de Faxinal passar a ter que se comunicar somente em português, como acontece quando ele tem de sair da T.I. para estudar, por exemplo, este continuará considerando que sua língua materna é a língua indígena. Ou seja, independente do grau de proficiência, ou da idade que tinha quando a aprendeu ou como aprendeu, muito mais por questão de pertencimento (AMARAL, 2010), de identidade, ela será sempre a sua língua materna, independentemente de quantas línguas ele aprenda ou faça uso depois.

Além da questão da proficiência em língua portuguesa e em língua indígena, esse trabalho também se propôs a fazer um levantamento inicial sobre as atitudes que os Kaingang de Faxinal manifestam em relação a essas línguas. Por essa razão, na seção seguinte abordaremos algumas noções importantes relativas aos estudos sobre atitudes linguísticas.

\subsection{Atitudes Linguísticas: conceitos}

Segundo Frosi, Faggion e Dal Corno (2010, p. 69), “As atitudes linguísticas constituem reações subjetivas a uma forma de linguagem. São juízos de valor sobre uma dada variedade linguística”. Complementando, Frosi, Faggion e Dal Corno (2010, p. 70) afirmam que:

A construção da identidade de um indivíduo é um processo contínuo ao longo da vida e é profundamente marcada pelas respostas dadas pelo grupo que o circunda, desde a infância. As atitudes em relação à língua de que ele é usuário e ao grupo sociolinguístico que ele representa podem determinar a sua relação com essa língua, com esse grupo e também com os demais grupos com que vai interagir. 
Como a língua está vinculada ao grupo a que pertencemos, o contexto social irá exercer grande influência sobre a língua e consequentemente as atitudes linguísticas também farão parte deste grupo e da sua identidade, pois:

Usar língua(s) faz parte da vida humana. É por meio dela que os usuários moldam, constituem e sustentam a vida social e a identidade social e individual. É natural, portanto, que toda pessoa, sendo falante de uma ou de diversas línguas em dado ambiente social, tenha visões, opiniões e atitudes sobre sua(s) própria(s) língua(s) e sobre a língua dos outros. Porém, no caso das atitudes linguísticas, o objeto da atitude não são as línguas em si, mas os grupos que as falam. As atitudes linguísticas representam, assim, um componente fundamental da identidade linguística do falante e possibilitam a leitura e compreensão do próprio comportamento linguístico. (CORBARI, 2012, p. 115).

Para Garcia (2009, p. 101), "as atitudes linguísticas funcionam como termômetros na avaliação da vitalidade de uma língua, em especial das minoritárias", como é o caso das línguas indígenas brasileiras. Ela também propõe que a visão deve partir da comunidade de língua minoritária, e para os estudos das atitudes linguísticas destes indivíduos é possível considerar três pontos ressaltados no mesmo texto por Garcia (2009, p. 101), quais sejam:

1) como os julgamentos da comunidade majoritária relativos à língua minoritária são percebidos e sentidos pela comunidade de língua minoritária; 2) quais são as reações aos julgamentos linguísticos externos, expressos na política de línguas da comunidade de língua minoritária; e 3) como a comunidade de língua minoritária age em relação à língua da comunidade majoritária.

Garcia (2009, p. 102) fala ainda das pressões externas, que influenciam as comunidades minoritárias e podem ser "de natureza histórica, econômica, política, entre outras", juntamente com os elementos internos que também influenciam as atitudes linguísticas das comunidades minoritárias. Neste contexto, as atitudes são movidas pela interação que existe entre a comunidade majoritária e a minoritária. Sendo assim, as atitudes linguísticas não são escolhidas livremente. No decorrer deste processo, cada comunidade reagirá de uma forma, não sendo possível prever suas atitudes com base apenas no estudo de um dos lados, ou seja, "é fundamental atentar-se para as atitudes linguísticas que, se vistas nos dois extremos, são favoráveis ou contrárias ao uso, à aquisição e à transmissão de uma ou mais línguas" (GARCIA, 2009, p. 102).

Como se pode observar, são muitas as perspectivas a partir das quais podemos estudar as atitudes, no entanto, quando falamos de língua, ou das atitudes linguísticas, devemos dar mais enfoque ao conjunto, não somente à língua em si, mas ao grupo de pessoas que falam determinada língua. É a língua que determina a interação social e que nos identifica como pertencentes a determinado lugar ou povo, de modo que ela faz parte da nossa identidade. Segundo Liebkind (1999 apud CORBARI, 2012, p. 115), "usar a língua influencia a formação da identidade de grupo, que, por sua vez, influencia os padrões de atitude e uso linguísticos". 


\section{Metodologia}

\subsection{Pesquisa qualitativa}

Nesta seção, vamos apresentar a metodologia que utilizamos nesta pesquisa. No geral, classificamos a pesquisa como de caráter qualitativo, embora utilize elementos de pesquisa quantitativa. De acordo com Godoy (1995, p. 21), segundo a perspectiva da pesquisa qualitativa:

Um fenômeno pode ser melhor compreendido no contexto em que ocorre e do qual é parte, devendo ser analisado numa perspectiva integrada. Para tanto, o pesquisador vai a campo buscando /I "captar" o fenômeno em estudo a partir da perspectiva das pessoas nele envolvidas, considerando todos os pontos de vista relevantes. Vários tipos de dados são coletados e analisados para que se entenda a dinâmica do fenômeno.

Como este trabalho visa identificar atitudes linguísticas e o grau de proficiência em língua Kaingang e portuguesa, a pesquisa qualitativa é a mais apropriada, pois os dados coletados são descritivos. Além disso, foi possível também coletar uma parte dos dados de forma quantitativa, o qual se levou em consideração a quantidade de pessoas que deram a mesma resposta. Segundo Bogdan e Biklei (1982 apud LÜDKE; ANDRÉ, 1986, p. 44):

A pesquisa qualitativa tem o ambiente natural como fonte direta dos dados e o pesquisador como instrumento chave. É predominantemente descritiva. Os dados coletados são mais uma forma de palavras ou figuras do que números. Estes dados incluem entrevistas transcritas, notas de campo, fotografias, produções pessoais, depoimentos ou outra forma de documento. A preocupação com o processo é maior do que com o produto. $\mathrm{O}$ pesquisador tem como interesse principal estudar um problema e verificar como ele se mostra nas atividades, procedimentos e nas interações cotidianas. O enfoque dos dados pesquisados deve sempre demonstrar a perspectiva dos significados atribuídos pelos participantes. A maneira como os informantes vivenciam e informam uma situação vivida é importante e singular a cada indivíduo. A análise dos dados segue um processo indutivo. Indução é um método mental por intermédio do qual, partindo-se de dados particulares, suficientemente constatados, infere-se uma verdade geral ou universal, não contida nas partes examinadas.

\subsection{Instrumento de levantamento de dados e participantes}

O principal instrumento de coleta de dados deste trabalho foi um questionário em português com dezenove (19) perguntas abertas. Mesmo tendo consciência de que o questionário é um instrumento limitado, optamos por ele em razão de uma série de fatores. Em primeiro lugar está o difícil acesso às comunidades indígenas, o que praticamente inviabiliza um número grande de visitas para coleta de dados; em segundo lugar está a situação delicada de conseguir autorização para entrar em uma Terra Indígena por parte das lideranças, que precisam conhecer a proposta de pesquisa antes de permitir a entrada; em terceiro, é preciso definir na escola, junto à equipe pedagógica, o melhor dia e horário para poder coletar os dados sem que se altere muito a rotina do local. 
Por todas essas razões, considerando que teríamos apenas um dia, 05 de maio de 2015, para conversar com professores e fazer o levantamento de dados, optamos pelo instrumento do questionário. Como estava escrito em português, contamos com a ajuda de professores intérpretes de Kaingang para orientar alguns alunos no preenchimento. Optamos também por questões abertas para que pudéssemos ter mais possibilidades de lançar um olhar além do quantitativo. Parte das perguntas era direcionada à avaliação da proficiência em língua portuguesa e em língua Kaingang e outra parte buscava fazer um levantamento das atitudes relativas a essas duas línguas, manifestadas pelos alunos participantes.

Os participantes eram ao todo vinte e nove (29) alunos do $6^{\circ}$ ano do ensino fundamental até o $3^{\circ}$ ano do ensino médio, todos Kaingang, moradores da Terra Indígena de Faxinal.

\section{Análise dos Dados}

\subsection{Proficiência em Língua Portuguesa e em Kaingang}

Os dados que nos permitem fazer observações sobre a proficiência em língua indígena foram obtidos a partir das questões 3 a 6 , sistematizados na Tabela 1 a seguir.

Tabela 1: Sistematização das respostas dadas a questões relacionadas à língua indígena

\begin{tabular}{|l|c|c|c|c|c|c|}
\hline \multicolumn{1}{|c|}{ Língua indigena } & Kaingang & Sim & $\begin{array}{c}\text { Mais ou } \\
\text { menos }\end{array}$ & $\begin{array}{c}\text { Não } \\
\text { respondeu }\end{array}$ & $\begin{array}{c}\text { Total de } \\
\text { pessoas }\end{array}$ & $\begin{array}{c}\text { Total } \\
\text { percentual }\end{array}$ \\
\hline $\begin{array}{l}\text { Você fala língua indigena? } \\
\text { Qual (is)? }\end{array}$ & $100 \%$ & $100 \%$ & & & 29 & $100 \%$ \\
\hline $\begin{array}{l}\text { Você sabe ler e escrever em } \\
\text { língua indigena? }\end{array}$ & & $79,30 \%$ & $10,35 \%$ & $10,35 \%$ & 29 & $100 \%$ \\
\hline $\begin{array}{l}\text { Seu pai fala língua } \\
\text { indigena? Qual? }\end{array}$ & $89,65 \%$ & $89,65 \%$ & & $10,35 \%$ & 29 & $100 \%$ \\
\hline $\begin{array}{l}\text { Sua mãe fala língua } \\
\text { indigena? Qual? }\end{array}$ & $96,55 \%$ & $96,55 \%$ & & $3,45 \%$ & 29 & $100 \%$ \\
\hline $\begin{array}{l}\text { Seus avós falam língua } \\
\text { indígena? Qual? }\end{array}$ & $96,55 \%$ & $96,55 \%$ & & $3,45 \%$ & 29 & $100 \%$ \\
\hline $\begin{array}{l}\text { Qual foi a primeira língua } \\
\text { que você aprendeu? }\end{array}$ & $100 \%$ & & & & & \\
\hline
\end{tabular}

\section{Fonte: Elaborado pela autora}

Como é possível observar na Tabela $1,100 \%$ dos alunos que responderam ao questionário disseram que falam língua indígena. Mas quando a pergunta era se sabem ler e escrever na língua indígena, apenas $79,30 \%$ responderam que sim, enquanto $10,35 \%$ responderam "mais ou menos" e 10,35\% não responderam. 
Essas respostas nos levam a pensar no papel da escola. Para saber falar uma língua não é preciso ir à escola quando se trata de uma língua falada no contexto em que a pessoa está inserida. No entanto, salvas raras exceções, para ler e escrever, a escola é fundamental. No caso da língua indígena, que é a língua materna dos Kaingang de Faxinal que entrevistamos, eles já a aprendem dentro de casa com os pais e avós desde pequenos. Nesta T.I., estão rodeados de pessoas que falam essa língua. Sendo assim, a responsabilidade da escola é ensinar a ler e escrever em língua indígena.

Os dados sobre proficiência em língua portuguesa vieram das respostas das perguntas 8,9 e 12 do questionário.

Tabela 2: Sistematização das respostas dadas a questões relacionadas à língua portuguesa

\begin{tabular}{|l|c|c|c|c|c|c|}
\hline \multicolumn{1}{|c|}{ Língua portuguesa } & Sim & Não & $\begin{array}{c}\text { Professores } \\
\text { não indígenas }\end{array}$ & $\begin{array}{c}\text { Não } \\
\text { indígenas em } \\
\text { geral }\end{array}$ & $\begin{array}{c}\text { Com } \\
\text { ambos }\end{array}$ & $\begin{array}{c}\text { Não } \\
\text { respondeu }\end{array}$ \\
\hline Você fala português? & $86,20 \%$ & $10,35 \%$ & & & & $3,45 \%$ \\
\hline $\begin{array}{l}\text { Com quem você fala } \\
\text { português? }\end{array}$ & $100 \%$ & & $58,63 \%$ & $24,13 \%$ & $3,45 \%$ & $13,79 \%$ \\
\hline $\begin{array}{l}\text { Você sabe ler e } \\
\text { escrever em } \\
\text { português? }\end{array}$ & & & & & & \\
\hline
\end{tabular}

Fonte: Elaborado pela autora

Em relação à pergunta "Você fala português?", 86,20\% dos alunos responderam afirmativamente, enquanto $10,35 \%$ responderam não saber e $3,45 \%$ não responderam. Já em relação à pergunta seguinte, "Com quem você fala português?", 58,63\% responderam que falam com os professores não indígenas, $24,13 \%$ com não indígenas em geral, 3,45\% com ambos, professores não indígenas e "brancos", e 13,79\% não responderam à questão.

A partir destes dados, podemos observar a importância do papel da escola dentro da Terra Indígena (doravante T. I.) de Faxinal, pois como 100\% dos indígenas moradores da T. I. falam a língua Kaingang isso pode causar uma certa dificuldade na comunicação tanto por parte dos professores que não são indígenas e lecionam na escola indígena e também por parte dos alunos. Como a escola exerce uma função importante como mediadora, principalmente nas séries iniciais, com relação às línguas Kaingang e portuguesa, ela vai desempenhar um papel fundamental tanto na preservação da língua indígena, neste caso, a língua Kaingang, como também na aprendizagem da língua portuguesa, que vai possibilitar o acesso ao que está fora da T. I. Como já mencionamos a questão da responsabilidade de a escola ensinar a ler e escrever a língua indígena, podemos perceber, a partir das respostas à pergunta "Você sabe ler e escrever em português?", que este papel também se aplica à língua portuguesa, sendo que $100 \%$ dos que responderam a esta pergunta disseram sim. 


\subsection{Leitura e Escrita em Língua Portuguesa e em Kaingang}

Com relação às habilidades nas duas línguas, podemos observar que se sobressai na língua portuguesa a de ler e escrever, pois $100 \%$ dos alunos entrevistados responderam que sabem ler e escrever em língua portuguesa.

No caso da proficiência em língua indígena, 79,30\% dos alunos responderam que sabem ler e escrever em Kaingang, ou seja, mais uma vez é possível reforçar o papel da escola dentro da aldeia, pois ela auxilia nesta questão.

\subsection{Atitudes Linguísticas}

Em relação à pergunta "Você acha importante falar língua indígena? Por quê?", $100 \%$ dos alunos responderam sim e as justificativas mais recorrentes foram as seguintes:

(01) Sim, para não esquecer quem você é.

(02) Sim, para não perder a cultura indígena.

(03) Sim, porque da nossa fala que eles acreditam que nós somos índios.

(04) Sim, é a nossa língua.

Já com relação à pergunta sobre a língua portuguesa, as respostas mais recorrentes foram as seguintes:

(01) Sim, porque para ser alguém na vida tem que saber português.

(02) Sim, porque se eu não aprender não vou poder ir pra cidade.

(03) Sim, (para) quando a gente se comunicar com os brancos.

A pergunta "Você acha importante saber ler e escrever em português? Por quê?" foi elaborada com o intuito de saber qual é a opinião dos estudantes indígenas com relação ao valor atribuído às competências de leitura e escrita (e não somente de competência oral), considerando que a cultura indígena até bem pouco tempo só se manifestava oralmente. Algumas das respostas que obtivemos foram as seguintes:

(01) Sim, porque quando nós vamos à cidade a gente escreve;

(02) Porque aprendemos novas palavras;

(03) Também é a nossa obrigação;

(04) Por que a gente vai chegar em qualquer lugar com ela.

Na sequência, o aluno deveria apontar qual língua ele achava "mais bonita".

Tabela 3 - Respostas à pergunta "Qual língua você acha mais bonita?"

\begin{tabular}{|l|l|l|l|}
\hline Atitudes & Kaingang & Português & Kaingang Português \\
\hline Qual a língua que você acha mais bonita? Por quê? & $68,97 \%$ & $20,68 \%$ & $10,35 \%$ \\
\hline
\end{tabular}

Fonte: Elaborado pela autora

Grande parte dos alunos que responderam ao questionário acha que a língua indígena Kaingang é a mais bonita: 68,97\%. Esta atitude, segundo Garcia (2009, p. 98), demonstra "[...] a existência de um sentimento étnico e de vínculos afetivos da comunidade para com a língua (Kaingang)", língua materna da totalidade dos participantes, na qual a grande maioria possui maior fluência, de acordo com os dados. Isso fica evidente nas explicações dadas para as respostas, como as seguintes: 
(01) "Nasci pra falar Kaingang";

(02) "Cada um conhece a sua língua";

(03) "Porque eu sei falar";

(04) “É nossa língua”;

(05) "Porque até as crianças sabem".

Com relação à pergunta “Qual a língua mais fácil?” Por quê?, os dados obtidos são os seguintes:

Tabela 4 - Respostas à pergunta "Qual é a língua mais fácil?"

\begin{tabular}{|l|l|l|}
\hline Atitudes & Kaingang & Português \\
\hline Qual é a língua mais fácil? Por quê? & $79,32 \%$ & $20,68 \%$ \\
\hline
\end{tabular}

Fonte: Elaborado pela autora

Esta manifestação pode ser explicada devido a diversos fatores que tornam a língua indígena uma língua resistente dentro da aldeia. Observando a sequência das respostas dadas à sequência das questões, o Kaingang não só é "mais fácil", como "mais bonito", além de ser a língua materna de todo o grupo, segundo os dados. Foram apresentadas algumas razões para que o Kaingang seja a língua mais fácil”:

(01) "Porque eu sei falar";

(02) "Porque eu nasci falando Kaingang";

(03) "Porque todos na aldeia já sabem";

(04) "Porque é a nossa língua nos já nasce Kaingang";

(05) "Desde criança já sabemos a nossa língua";

(06) "Porque nós índios aprendemos o Kaingang primeiro".

Em seguida, a Tabela 5 nos mostra dados referentes à resposta à questão "Qual é a língua mais importante?"

Tabela 5 - Respostas à pergunta "Qual é a língua mais importante?"

\begin{tabular}{|l|l|l|l|}
\hline Atitudes & Kaingang & Português & $\begin{array}{l}\text { Kaingang e } \\
\text { Português }\end{array}$ \\
\hline Qual é a língua mais importante? Por quê? & $48,28 \%$ & $44,83 \%$ & $6,89 \%$ \\
\hline
\end{tabular}

Fonte: Elaborada pela autora

Para quem respondeu que a língua Kaingang é a mais importante, esta atitude está relacionada ao sentimento de orgulho pela língua materna, manifestado nas respostas à pergunta "Qual é a língua mais bonita?", por exemplo. Dizem que o Kaingang é mais importante, porque, segundo os indígenas, a língua também representa a identidade indígena nesta comunidade. As respostas que justificam essa opinião são as seguintes: 
(01) "Não podemos deixar nossa fala por outra";

(02) "É importante que a gente fala e escreve";

(03) "Kaingang, porque na aldeia todo mundo fala";

(04) "Nois nasci pra falar Kaingang".

\section{Considerações finais}

Os dados levantados mostraram que, apesar de muitos acharem que as línguas indígenas brasileiras estão morrendo e, em geral, não são valorizadas pelos seus falantes, a realidade de Faxinal é diferente. Ao analisar os dados relativos à proficiência, concluímos que, para a grande maioria dos participantes, o Kaingang é a língua materna e a língua mais usada no dia a dia; a grande maioria dos participantes vem de uma família em que todos os membros também falam Kaingang. Já em relação à língua portuguesa, a grande maioria declarou que começou a aprendê-la na escola, com 5 ou 6 anos. Usam o português para se comunicar com professores não indígenas, pessoas da cidade e visitantes não indígenas que vão à aldeia.

Em relação às atitudes linguísticas, verificamos, por meio dos levantamentos, que as crianças e os adolescentes da Terra Indígena de Faxinal demonstram muito orgulho de ser indígena e de falar a língua indígena Kaingang, pois a consideraram a mais bonita, mais fácil e também a mais importante. Uma atitude de valorização da língua e consequentemente da sua própria identidade. Com relação à língua portuguesa, há reconhecimento da importância de falar, ler e escrever em português, pois é a língua portuguesa que vai propiciar "ser alguém na vida" e "se comunicar com os brancos".

Por fim, a pesquisa que realizamos revelou que a análise da questão da proficiência e das atitudes deve ser feita de forma mais cuidadosa, levando em conta o contexto da escola indígena e da própria comunidade, com suas especificidades, que constituem a identidade do sujeito e a sua permanência no meio. As discussões acerca das comunidades indígenas, da escola e das línguas indígenas é importante, pois ainda há muito a se pesquisar. Os indígenas são povos que possuem uma riqueza cultural e uma forma de viver e enxergar a vida muito peculiar, que a todo o momento nos surpreendem.

\section{REFERÊNCIAS}

ALMEIDA, S. A. de. Bilinguismo e Educação Bilíngue Intercultural: os Apinayé e o uso das línguas apinayé e portuguesa nos seus domínios sociais. Anais do VII Congresso Internacional da Abralin, Curitiba, 2011.

AMARAL, L. Bilinguismo, aquisição, letramento e o ensino de múltiplas línguas em escolas indígenas no Brasil. CADERNOS DE EDUCAÇÃO ESCOLAR INDÍGENA Faculdade Indígena Intercultural. Editora UNEMAT, 2011.

ANDRIOLI, L. R.; MORI, N. N. R.; FAUSTINO, R. C. Leitura e escrita: estudo sobre a alfabetização e o bilinguismo Kaingang na Terra Indígena Faxinal. Seminário de Pesquisa do PPE, Maringá, 2010.

CAVALCANTI, M. C. Estudos sobre educação bilíngue e escolarização em contextos de minorias linguísticas no Brasil. D.E.L.T.A., v. 15, n. esp., p. 385-417, 1999. 
CORBARI, C. C. Crenças e Atitudes Linguísticas de Falantes de Irati (PR). Signun Universidade Estadual de Londrina, Paraná, v. 15, n. 1, p. 111-127,2012.

FAUSTINO, R. C. Teoria histórico cultural e educação indígena: uma experiência com a escola dos Kaingang no Paraná. Currículo sem Fronteiras, Maringá, 2012.

FROSI, M. V.; FAGGION, M. C.; DAL CORNO, M. O. G. Estigma: Cultura e Atitudes Linguísticas. Rio Grande do Sul: Ed. EDUCS, 2010.

GARCIA, S. M. de. O papel das atitudes linguísticas na manutenção ou não da língua indígena em comunidades indígenas bilíngues: o caso Ipegue/Terena. Revista Eletrônica Via Litterae, Anápolis, v. 1, n. 1, p. 99-118,2009

LÜDKE, M.; ANDRÉ, M. E. D. A. Pesquisa em educação: abordagens qualitativas. São Paulo: EPU, 1986.

RODRIGUES, I. C. VENH JYKRE SI: Memória, Tradição e Costume entre os Kaingang da T. I. Faxinal Candido de Abreu Paraná. 2012. 155 f. Tese (Doutorado em Ciências Sociais) - Pontifícia Universidade Católica de São Paulo, São Paulo, 2012.

SPINASSÉ, K. P. Os conceitos Língua Materna, Segunda Língua e Língua Estrangeira e os falantes de línguas alóctones minoritárias no Sul do Brasil. Revista Contingentia, v. 1, n. 1, p. 01-10, 2006.

Recebido em: 29/08/2017

Aprovado em: 06/11/2017 